\title{
DISCRIMINAÇÕES CONDICIONAIS ENTRE ESTÍMULOS VISUAIS E TESTES DE SIMETRIA EM MELIPONAS ${ }^{1}$
}

CONDITIONAL VISUAL DISCRIMINATIONS AND SYMMETRY PROBES IN

\author{
MELIPONAS
}

Antonio Maurício Moreno

UNIVERSIDADE DE SÃO PAULO, BRASIL JULIA ZaNETTI RocCA

UNIVERSIDADE FEDERAL DE SÃO CARLOS, BRASIL

Luiz Marcelino de Oliveira

UNIVERSIDADE DE SÃO PAULO, BRASIL

E Deisy das Graças de SOUZa

UNIVERSIDADE FEDERAL DE SÃO CARLOS, BRASIL

\section{RESUMO}

Oito melíponas (Melipona quadrifasciata) foram expostas a uma versão adaptada do procedimento de emparelhamento arbitrário com o modelo (matching-to-sample) em que a presença ou ausência de luz era empregada como estímulo condicional e as cores azul e amarelo como estímulos discriminativos. As cores eram apresentadas por semicírculos de material emborrachado sustentados por duas caixas retangulares de madeira, cada uma posicionada sobre uma caixa experimental a uma distância de $15 \mathrm{~cm}$ uma da outra. Cada lâmpada estava localizada sobre uma das caixas. As caixas experimentais eram de material acrílico com um painel superior de alumínio. Cada caixa era equipada com um alimentador operado externamente por uma haste e possuía um conjunto de pequenos orifícios no painel de alumínio que davam acesso ao xarope. Uma abelha podia voar da colméia para o aparato experimental e obter o xarope condicionalmente ao pouso direto sobre o estímulo de comparação definido como $\mathrm{S}+$ em uma tentativa particular. Depois de instalada a linha de base, foram conduzidas sondas de simetria em extinção, intercaladas com tentativas de linha de base. Nas sondas, os discos coloridos tinham a função de estímulos condicionais (as duas caixas mostravam os discos de uma mesma cor, azul ou amarelo) e a presença e a ausência de luz eram usadas como estímulos discriminativos. As discriminaçôes condicionais foram estabelecidas com todas as abelhas e seis entre as oito abelhas alcançaram o critério de simetria emergente (ao menos cinco tentativas entre seis). Estes resultados estendem achados prévios sobre discriminações condicionais e emparelhamento de identidade em abelhas. Contudo, no presente procedimento os estímulos tinham posição fixa, o que permite questionar se os comportamentos observados revelam propriedades simétricas (emergentes) ou apenas o controle por componentes de estímulos compostos (diretamente aprendidos).

Palavras-chave: discriminação condicional, simetria, abelhas (Melipona quadrifasciata).

\section{ABSTRACT}

Eight adult, worker bees (Melipona quadrifasciata) were exposed to an adapted version of the matchingto-sample procedure in which the presence or absence of lights was used as the conditional stimuli and yellow and blue colors were the discriminative stimuli. The color stimuli were presented as semi-circles of opaque rubber material located on top of two rectangular boxes, located $15 \mathrm{~cm}$ apart from each other. The lights were located one

\footnotetext{
1 Trabalho apoiado pelo CNPq e apresentado no XII Encontro da Associação Brasileira de Psicoterapia e Medicina Comportamental e $2^{\text {nd }}$ International Conference of the Association for Behavior Analysis (Campinas, Brasil, 12 a 15 de outubro de 2004). Os autores agradecem a colaboração do Dr. Isaías Pessotti em relação a inúmeros aspectos do procedimento e ao Dr. Ademilson Spencer Egea Soares, do Departamento de Genética da Universidade de São Paulo, em Ribeirão Preto, que cedeu a colméia original. Endereço para correspondência: Rua Jesuíno de Arruda, 1365 - Apto. 404, bloco 10, Jardim São Carlos - São Carlos - SP - CEP: 13560-642. E-mail: mauricio_amm@hotmail.com.
} 
above each box. The experimental boxes were custom-made, constructed of gray plexiglass with an aluminum top panel. Each box was equipped with a feeder operated from outside by a handle and small holes on a circumscribed area on the top gave access to syrup. The bee would fly from the hive to the experimental setting and would obtain syrup conditional upon flying to the box holding the comparison stimulus defined as $S+$ on a particular trial. After the baseline was established, symmetry probes interspersed with baseline trials were conducted in extinction. During the symmetry probes the colored disks had the function of conditional stimuli (the two boxes held disks of the same color, either blue or yellow) and the presence and absence of light were used as discriminative stimuli. The conditional discriminations were established with all bees and six out of eight reached the criterion for emergent symmetry (at least five trials out of six). These results extended previous findings for conditional discriminations and identity matching with bees. For symmetry tests, however, in the present procedure the stimuli had fixed positions, an issue which raises questions as to whether the observed behavior reveals symmetric (emergent) properties or just (learned) joint-control by components of a compound stimulus.

Key words: conditional discriminations, symmetry, bees (Melipona quadrifasciata).

Os estudos conduzidos por Isaías Pessotti, na Universidade de São Paulo, nas décadas de 60 e 70, replicaram, com abelhas, os procedimentos básicos para instalação e manutenção de comportamento operante em animais, incluindo modelagem, esquemas de reforço, punição, discriminação simples e condicional (Pessotti, 1964, 1965, 1967a, 1967b, 1969, 1971a, 1971b, 1981; Pessotti \& Lé Senechal, 1981; Pessotti \& Otero, 1981; Traina \& Pessotti, 1964-1965). Um aspecto original desses trabalhos foi o emprego de uma barra como operandum; usou-se a resposta de pressão à barra como um operante de fácil registro e que podia produzir automaticamente as conseqüências programadas, sem a interferência direta do experimentador.

De maior interesse para o presente estudo é a pesquisa em que Pessotti $(1969,1981)$ estabeleceu discriminações condicionais em abelhas da espécie Melipona rufiventris. Quando a abelha pressionava a barra, essa resposta era automaticamente registrada por um sistema eletro-mecânico e operava um interruptor, produzindo a apresentação de uma solução de açúcar. Dois aparelhos iguais, contendo o dispositivo da barra e do bebedouro, posicionados lado a lado, eram cobertos com discos de material plástico (ambos azuis ou ambos amare- los). Adicionalmente, uma peça retangular do mesmo material e da mesma cor era posicionada entre os dois aparelhos.

No interior de cada aparelho estava localizada uma lâmpada. A cada tentativa, cada um dos dois aparelhos era apresentado com um disco de uma cor (a cor era a mesma nos dois aparelhos e na peça retangular entre esses aparelhos) e esta cor era definida como estímulo modelo. Os estímulos de comparação eram constituídos pelas lâmpadas de 6 volts: um dos aparelhos era apresentado com uma lâmpada acesa, o outro era apresentado com uma lâmpada apagada.

Para estabelecer as discriminações condicionais, depois de modelada a resposta de pressão à barra, Pessotti $(1969,1981)$ começou por ensinar a cada uma de dez operárias adultas da espécie Melipona rufiventris uma discriminação simples entre luz acesa e luz apagada, seguida por reversão da discriminação, isto é, para metade dos sujeitos para os quais a lâmpada acesa era $S_{+}$, a lâmpada apagada passou a ser o $S_{+}$, enquanto a lâmpada acesa tornouse S-; o inverso foi feito para a outra metade de sujeitos que começaram com luz apagada como S+. Nesse momento, o estímulo modelo era posicionado junto aos aparelhos, os discos azuis quando a lâmpada acesa era o $S+$ e os amarelos 
quando a lâmpada apagada era o $S_{+}$(ou o inverso, para a outra metade de abelhas). O processo de reversão foi sistematicamente repetido, através de mudanças sucessivas nas funções de $S+$ e S-, com critérios de aquisição em cada reversão. Quando as reversões resultavam rapidamente em mudança no índice de discriminação, os estímulos modelo passaram a ser alternados semi-aleatoriamente, independentemente do índice de discriminação. Instaladas as discriminações condicionais, foram realizados testes de reversão das discriminações. No entanto, esta era uma reversão entre as funções dos estímulos, não se caracterizando como um teste de simetria (em que os modelos passam a funcionar como comparações e vice-versa): cada modelo passava a ser o estímulo condicional para a seleção do estímulo que havia sido empregado como $S$ - na sua presença, durante a linha de base de discriminações condicionais. Tais testes foram bem sucedidos, revelando que as abelhas revertiam rapidamente o comportamento, em função das mudanças na função dos estímulos condicionais. Além disso, as respostas nas tentativas de linha de base mostraram alto grau de acurácia, o que nem sempre tem sido conseguido com outras espécies animais.

Esse estudo de Pessotti tornou-se clássico, não apenas por demonstrar o estabelecimento de discriminaçôes condicionais em abelhas, mas, sobretudo, por ter estabelecido as condições que possibilitariam usar a abelha como modelo experimental para o estudo de processos comportamentais complexos.

Desempenhos complexos em abelhas, como percorrer ou voar em labirintos, sob controle condicional, também têm sido relatados (e.g., Giurfa, Zhang, Jenett, Menzel, \& Srinivasan, 2001; Zhang, Lehrer, \& Srinivasan,
1999). Usando procedimentos de emparelhamento de identidade (Cumming \& Berryman, 1965) e de emparelhamento por singularidade (Berryman, Cumming, Cohen, \& Johnson, 1965), Giurfa e colaboradores (2001) ensinaram as relaçôes de "igualdade" e de "singularidade" empregando como estímulos figuras de uma cor homogênea, figuras com padróes em preto e branco e, ainda, odores. A resposta da abelha era a de percorrer um labirinto em Y, em que o modelo era apresentado na entrada $\mathrm{e}$ os dois estímulos de comparação eram apresentados nos braços do Y. Desse modo, o procedimento era o de emparelhamento com atraso, porque quando a abelha se encontrava diante do ponto de escolha, o estímulo modelo encontrava-se atrás dela. As abelhas aprenderam a tarefa, quer a escolha definida como correta fosse o estímulo idêntico ao modelo, ou o estímulo diferente do modelo. Desempenhos positivos também ocorreram em "testes de transferência” - em que foram utilizadas cores, padrôes ou aromas inéditos durante os testes e, ainda assim, as abelhas continuaram fazendo escolhas por identidade ou por singularidade, de acordo com o que haviam aprendido na linha de base. Esses testes podem ser considerados como testes de identidade e singularidade generalizadas (Catania, 1999).

Os desempenhos complexos apresentados por abelhas, que atestam aprendizagens relacionais, encontram-se entre os precursores ou requisitos para a formação de classes de estímulos equivalentes. Estímulos são considerados como membros de uma classe de equivalência quando as relações entre eles apresentam as propriedades de reflexividade, simetria e transitividade (de Rose, 1993; Sidman \& Tailby, 1982). As demonstrações prévias com discriminações condicionais, com reversōes de 
tais discriminaçôes (Pessotti, 1969, 1981) e com identidade e singularidade generalizadas (Giurfa et al., 2001), sugerem a possibilidade de que tais organismos também relacionem estímulos, sem treino direto, pela emergência de simetria e transitividade. Propriedades emergentes derivam das contingências de reforço, mas não são estabelecidas diretamente por elas.

Contudo, diferentemente da extensa literatura sobre desempenhos emergentes em humanos, a demonstração de equivalência em infra-humanos (por meio da constatação das propriedades de simetria e de transitividade) tem sido rara e, freqüentemente controvertida. Por exemplo, McIntire, Cleary e Thompson (1987) relataram desempenhos emergentes com macacos. Nesse estudo, seis cores (numeradas de 1 a 6) foram utilizadas como estímulos e dois tipos de resposta foram definidos. A resposta 1 , definida por duração, consistia em pressionar uma barra e mantê-la assim por 3,5 segundos. A resposta 2, definida por número, consistia em uma série de oito respostas consecutivas (razão fixa ou FR 8). Os sujeitos aprenderam a emitir a resposta 1 diante dos estímulos 1,3 e 5 e a resposta 2 diante dos estímulos 2, 4 e 6; também aprenderam a selecionar a cor 1diante da cor 1 (identidade); a cor 3 diante da cor 1 (emparelhamento arbitrário) e a cor 5 diante da cor 3 (emparelhamento arbitrário), apresentando a resposta 1 tanto diante do estímulo modelo (que, então produzia dois estímulos de comparação), quanto diante do estímulo de comparação definido como correto. Os sujeitos também aprenderam a responder à cor 4 diante da cor 2; à cor 6 diante da 4 e à cor 2 diante da 2 , com a resposta 2 (FR 8) . Sondas conduzidas em extinção demonstraram que os macacos respondiam com a resposta 1 aos estímulos 1, 3 e 5 e com a resposta 2 aos estímulos 2 , 4 e 6 . Contudo, questiona-se a demonstração de relações emergentes: por exemplo, Hayes (1989) argumenta que o responder mediado por respostas caracteriza classes funcionais, mas não classes de equivalência (mas ver também Sidman, 1994, sobre a possibilidade de que respostas e reforçadores também façam parte de classes de equivalência).

São numerosos os estudos que fracassaram em demonstrar a formação de relações de equivalência em infra-humanos. Lipkens, Kop e Matthijs (1988), em um estudo com pombos, obtiveram resultados negativos em testes de simetria e de transitividade (a proporção de acertos foi próxima de $50 \%$ nos dois testes). Em um estudo conduzido por Kamil e Sacks (1972), pombos eram ensinados a bicar uma chave lateral vermelha quando a chave central era vermelha e a bicar a chave lateral verde quando a chave central era verde. Ou seja, os pombos foram treinados em um procedimento típico de emparelhamento com o modelo por identidade: um estímulo definido como modelo era apresentado em uma chave central; o sujeito respondia a essa chave, que era desligada e, imediatamente, os outros dois discos laterais eram iluminados (zero-delay matching to sample); a resposta ao disco "igual" ao disco central determinava a apresentação de reforço, enquanto a resposta ao outro disco ("diferente" do disco central) era colocada em extinção. As possibilidades de combinação ("configuração") dos estímulos a cada tentativa poderiam ser representadas como: $R^{*} R G, G R R^{*}, R^{*} G^{*}$ e $\mathrm{G}^{*} \mathrm{GR}$, onde uma letra seguida por um asterisco indica o estímulo de comparação correto - vermelho (R) ou verde (G). Durante o treino, qualquer uma dessas configurações poderia ser apresentada, com exceção de $G^{*} G R$. 
Assim, quando o modelo apresentado era a chave verde, o comparação verde aparecia na chave direita, nunca na chave esquerda. Durante testes de relações emergentes, além das três configurações apresentadas durante o treino, a combinação $G^{*} \mathrm{GR}$ também era agora apresentada. Nenhum dos quatro pombos treinados respondeu para essa nova configuração, diante da qual um dos pombos chegou a emitir mais de 150 respostas incorretas consecutivas. Esse resultado foi considerado como uma evidência de que a localização dos estímulos poderia controlar o responder. Do mesmo modo, Iversen, Sidman e Carrigan (1986) mostraram que o desempenho de macacos em um procedimento de emparelhamento com o modelo tendia a se deteriorar nos testes, quando o modelo era apresentado não apenas na chave central, mas também nas chaves laterais. Os autores sugeriram que a interpretação de discriminação condicional ou relação de equivalência em animais em um procedimento de emparelhamento com o modelo deveria ser considerada com cautela.

A partir dos resultados desses estudos, passou-se a considerar também, além da questão sobre quais condiçôes de treino de discriminação condicional levam à formação de relações de equivalência, a questão sobre quais as condiçôes de treino que permitem interpretar com mais segurança que um suposto desempenho é "verdadeiramente" emergente, e não um desempenho controlado por variáveis não definidas pelo experimentador.

Em um estudo mais recente, Schusterman e Kastak (1993) relataram a formação de classes de equivalência em um leãomarinho (Zalophus californianus). As primeiras relaçóes de simetria foram explicitamente ensinadas, após resultados negativos nos tes- tes, e posteriormente novas relações de simetria e transitividade foram testadas - 12 classes de equivalência foram estabelecidas por meio de um procedimento de emparelhamento com o modelo. Posteriormente, o sujeito foi exposto a sessóes de teste de equivalência em que foram utilizadas 18 novas classes potenciais de estímulos. Relações de equivalência foram demonstradas para 14 classes de um total de 18 classes potenciais testadas. Comentando os resultados negativos obtidos por Dugdale e Lowe (1990) e por Tomonaga, Matsuzawa, Fujita e Yamamoto (1991), que falharam em demonstrar relações de simetria em macacos (Pan troglodytes), Schusterman e Kastak (1993) formularam, com base em seu próprio estudo, a hipótese de que aqueles pesquisadores poderiam ter obtido melhores resultados se tivessem empregado um programa de treino que propiciasse aos sujeitos uma experiência maior com o procedimento de emparelhamento com o modelo, com exemplos em que a função do modelo e dos comparações fosse intercambiada ainda nos treinos, e não apenas nos testes. Posteriormente, Lionello e Urcuioli (2002) treinaram pombos em um procedimento no qual os modelos apareciam, ainda durante o treino, em outras posições, além da chave central. Em um dos experimentos desse estudo, a relação de simetria foi explicitamente ensinada com alguns estímulos. Nos testes, entretanto, nenhuma evidência de simetria, ou mesmo de reflexividade, foi obtida.

Segundo Dube, Mcllvane, Callahan e Stoddard (1993), têm sido apresentadas duas interpretaçōes para o fracasso em demonstrar relações de equivalência em infra-humanos: uma interpretação qualitativa e uma interpretação quantitatitva. A interpretação qualitati$v a$, apontando diferenças entre espécies, sus- 
tenta que a formação de equivalência requer associaçōes neurais (redes neurais) que somente são encontradas no sistema nervoso humano. A interpretação quantitativa, por outro lado, sustenta que o fracasso em demonstrar equivalência em infra-humanos se deve ao emprego de procedimentos inadequados (com relação ao treino, ao teste, ou a ambos). Uma conseqüência dessa interpretação, segundo os autores, é que os humanos, mas não os animais de laboratório, provavelmente adquirem uma experiência pré-experimental que possibilita a aquisição de pré-requisitos comportamentais necessários aos desempenhos positivos em testes de equivalência.

Baseados na última interpretação, os trabalhos de Galvão, Barros e McIlvane (Barros \& Galvão, 2003; Barros, Galvão \& Mcllvane, 2002) vêm demonstrando que a programação cuidadosa de contingências resultou na emergência de identidade generalizada em Cebus apella e na emergência de simetria para um macaco dessa espécie. Nesses estudos, os sujeitos aprenderam discriminações simples entre os estímulos que seriam depois empregados em um treino de emparelhamento de identidade e, para o macaco que apresentou resultados em testes de simetria, o estabelecimento da linha de base de discriminações condicionais entre estímulos diferentes (emparelhamento arbitrário) foi conseguido graças à transformação gradual do emparelhamento de identidade em emparelhamento arbitrário, por meio de um procedimento de modelagem do estímulo modelo (Zigmont, Lazar, Dube \& McIlvane, 1992) no qual a forma do estímulo modelo, que de início era igual ao comparação definido como correto, foi gradualmente modificada até que a discriminação se tornasse uma discriminação arbitrária.
Seguindo a mesma linha de raciocínio, o presente estudo assume o pressuposto de que a demonstração de relações de equivalência em infra-humanos pode depender de condiçôes experimentais e procedimentos adequados e que a investigação com abelhas pode ser útil na busca por condições que favoreçam a emergência de desempenhos novos em infra-humanos.

O objetivo deste estudo, realizado com melíponas, foi estabelecer discriminações condicionais entre pares de estímulos visuais, como linha de base para a condução de testes de simetria. Para estabelecer as discriminações condicionais, procurou-se replicar o procedimento geral empregado por Pessotti $(1969,1981)$, com algumas adaptações em relação a configuraçóes de estímulos, ao operante e aos critérios de aprendizagem, que serão detalhadas na seção de procedimento.

\section{MÉTODO}

\section{Sujeitos}

Foram empregadas como sujeitos oito abelhas da espécie Melipona quadrifasciata (vulgarmente conhecida como Mandaçaia), operárias, em idade adulta, experimentalmente ingênuas, todas procedentes de uma mesma colméia instalada no Laboratório de Psicologia da Aprendizagem do Departamento de Psicologia da Universidade Federal de São Carlos. A colméia encontrava-se instalada sobre um aparador junto da janela e sua entrada era posicionada na direção do batente esquerdo da janela, de modo que ao sair da colméia, uma abelha podia voar tanto para dentro da sala, como para o ambiente natural.

Uma característica importante dos sujeitos é que o xarope funciona como um reforçador 
poderoso, porém não está sujeito aos efeitos de operações estabelecedoras (Michael, 1982) como privação e saciação, uma vez que não é consumido, mas depositado na colméia. Assim, uma vantagem desse organismo é que ele pode trabalhar por muitas horas, sem alteração na "motivação" (Pessotti, 1964; 1969). Outro aspecto importante, é que a abelha dispensa alojamentos especiais (sua "moradia" é a colméia) e que se pode trabalhar com operantes realmente livres, no sentido que o operante requerido pelo experimentador compete com os comportamentos mantidos pelo ambiente natural, na busca por alimento (xarope e pólen) para a colméia.

Por outro lado, uma dificuldade que se apresenta na utilização da melípona operária como sujeito se refere ao seu tempo de vida relativamente curto. Em geral, não é possível conduzir mais do que algumas poucas sessōes (cada uma com duração entre 8 e 10 horas). No presente estudo, cada sujeito foi treinado em no máximo duas sessões. Apenas dois sujeitos responderam a mais de 300 tentativas, um número bastante reduzido em comparação a procedimentos semelhantes conduzidos com outras espécies.

\section{Material e equipamentos}

Os aparelhos utilizados foram duas vasilhas de acrílico em forma de paralelepípedo medindo $12,6 \mathrm{~cm} \mathrm{X} \mathrm{7,0} \mathrm{cm} \mathrm{e} \mathrm{3,5} \mathrm{cm} \mathrm{de} \mathrm{altu-}$ ra (ver Figura 1). Cada aparelho era fechado na parte superior por uma placa metálica, que tinha um conjunto de pequenos orifícios em forma de cruz em uma das extremidades (bebedouro), onde a abelha podia inserir a glossa e sugar o xarope. Cada aparelho continha um reservatório localizado abaixo do bebedouro, onde era acondicionada uma solução de açúcar a 50\%. Dentro de cada bebedouro havia um aparato metálico em forma de $\mathrm{T}$ em cujas extremidades encontrava-se uma concha. A haste mais longa do $T$ estendia-se para fora do bebedouro e terminava em um pegador, que podia ser girado para a direita ou para a esquerda, e permitia a manipulação pelo experimentador, aproximando ou afastando a concha do bebedouro. No presente estudo foi empregada apenas uma concha em cada aparelho (a da esquerda, no aparelho esquerdo e a da direita no aparelho direito). A concha fornecia aproximadamente $0,5 \mathrm{ml}$ de xarope. Os dois aparelhos eram dispostos sobre uma mesa de tampo branco, posicionada a uma distância de aproximadamente $1,5 \mathrm{~m}$ da colméia. A distância entre os dois aparelhos era de $20 \mathrm{~cm}$. Sobre cada aparelho era acoplada uma caixa de madeira retangular, medindo $15,6 \mathrm{~cm} \mathrm{X} \mathrm{13,0} \mathrm{cm}$ e 4,0 cm de altura. A caixa, pintada de preto, continha um disco de $12 \mathrm{~cm}$ de diâmetro feito de material emborrachado (E.V.A.) e disposto de tal modo que metade dele ficava dentro da caixa e a outra metade ficava exposta, posicionada sobre a superfície do tampo metálico que incluía o bebedouro. Em cada metade do disco, havia um orifício circular de 1,5 $\mathrm{cm}$ de diâmetro, a uma distância de $3,5 \mathrm{~cm}$ do centro do disco, que coincidia com o bebedouro do aparelho, quando aquela metade estivesse sobre a caixa experimental. As duas metades do disco tinham cores diferentes, uma azul, a outra amarela. A cada tentativa, o disco era girado manualmente, de modo que uma metade se tornava exterior à caixa de madeira e a outra era mantida oculta dentro dela. Uma lâmpada incandescente branca de 7W de potência era posicionada acima do bebedouro de cada aparelho, a uma distância de $6 \mathrm{~cm}$. As lâmpadas eram ligadas a filtros de linha e po- 

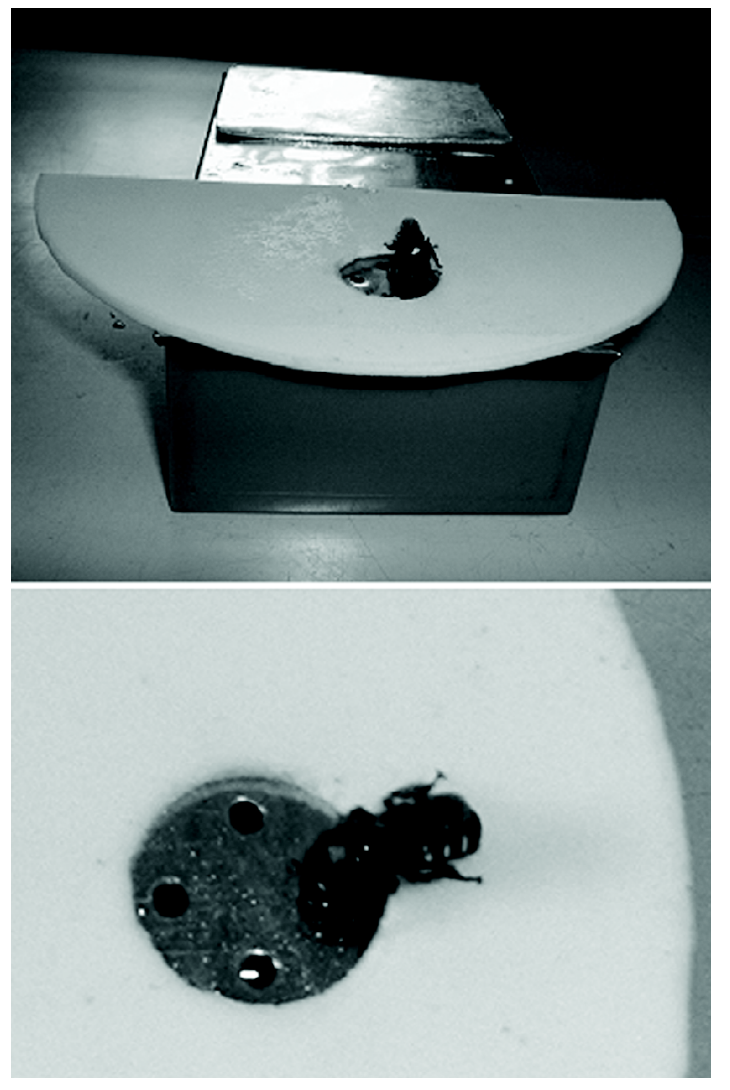

Figura 1. Situação experimental no pré-treino, quando era feita a modelagem do pouso sobre o aparelho e a modelagem da resposta de sugar no bebedouro. diam ser ligadas ou desligadas manualmente, por meio de interruptores.

\section{Estímulos}

Foram empregados estímulos visuais luminosos (lâmpada acesa ou apagada) e cores (azul e amarelo). Os estímulos luminosos eram apresentados pelas lâmpadas de 7W, que podiam estar simultaneamente acesas, simultaneamente apagadas, ou uma acesa e outra apagada. Foram usadas duas lâmpadas, uma sobre cada aparelho, para garantir que, em cada aparelho, esse estímulo estivesse localizado próximo ao estímulo colorido. As cores amarelo e azul eram apresentadas pelo semicírculo recoberto por E.V.A (ver Figura 2). Quando usados como modelo, os dois estímulos eram iguais e apresentados simultaneamente nos dois aparelhos (duas lâmpadas acesas, duas apagadas, dois discos amarelos ou dois discos azuis). Quando empregados como os estímulos de comparação, cada membro do par era apresen-

\section{A. Linha de Base das Discriminações Condicionais}
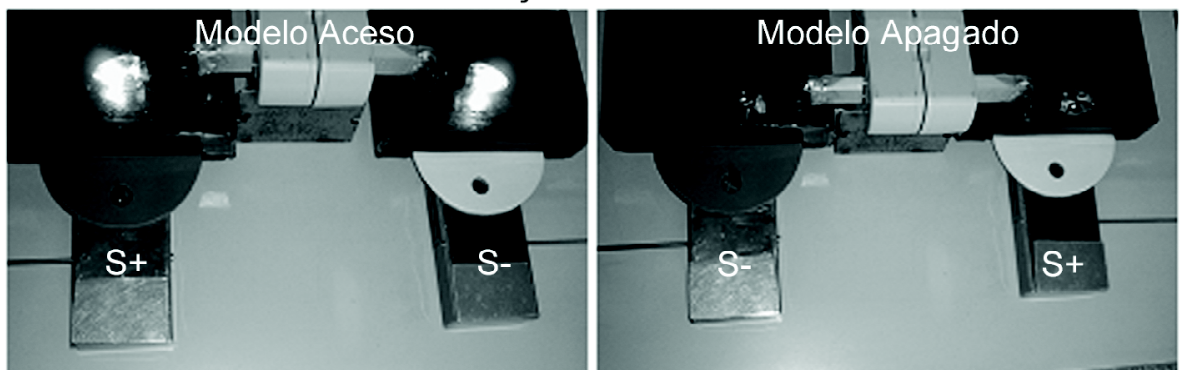

B. Teste de Simetria
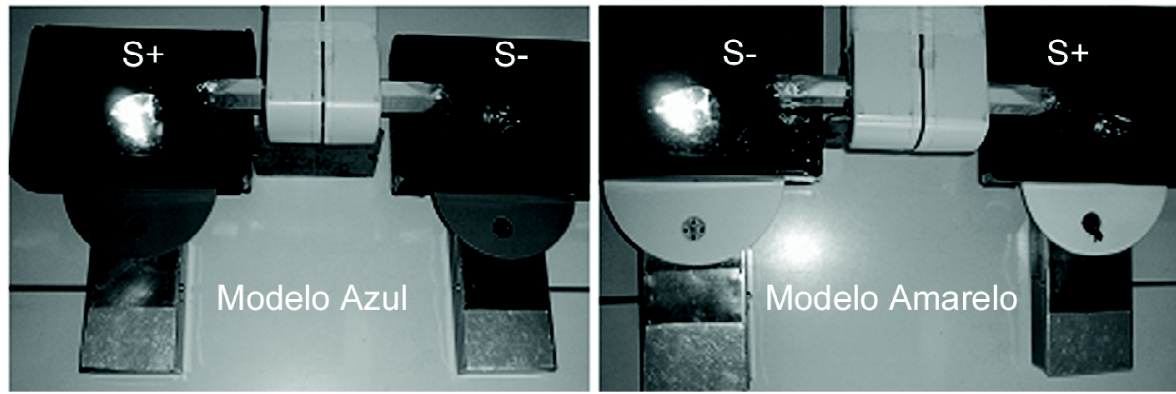

Figura 2. A. Disposição dos estímulos nas situações de estabelecimento de discriminaçôes condicionais (A) e nos Testes de simetria (B). 
tado em um dos aparelhos (lâmpada acesa versus lâmpada apagada; disco amarelo versus disco azul). Para conveniência na descrição de procedimentos e resultados, será empregado um código alfa-numérico na descrição dos estímulos; as letras indicam o conjunto de estímulos ( $\mathrm{A}=$ luzes e $\mathrm{B}=$ cores $)$ e os números indicam os dois estímulos em um conjunto. A1 indicará luz acesa e A2, luz apagada; B1 indicará cor azul e B2, cor amarela.

\section{Procedimento}

Identificação do sujeito. No início da sessão, um pires contendo xarope era posicionado próximo à entrada da colméia. Poucos minutos depois, várias abelhas encontravam-se pousadas sobre o pires. Cada abelha gastava aproximadamente um minuto sugando o xarope, antes de voar de volta para a colméia.

Nesse momento, quando várias abelhas visitavam o pires, uma delas recebia uma marca de tinta sobre o dorso, feita com tinta guache (cf. Pessotti, 1964), como mostra o painel superior da Figura 1. A marca era feita utilizando-se um pincel fino comum, quando a abelha encontrava-se pousada, sugando xarope. A marca de tinta mantinha-se nítida ao longo de vários dias, tempo suficiente para a realização de todo o procedimento. Eventualmente, se a tinta se desvanecia, a marca era refeita.

O trabalho era conduzido com apenas uma abelha por vez. Outras abelhas que entrassem na sala experimental eram afastadas manualmente e impedidas de se aproximarem do pires. Depois de dez ou vinte minutos sem acesso ao xarope, essas abelhas deixavam de voar em direção a esse pires.

Modelagem de pouso sobre o aparelho e da resposta de sugar no bebedouro. O pires conten- do xarope era gradualmente deslocado em direção a uma das caixas experimentais localizadas sobre a mesa (nesta fase, a outra caixa permanecia coberta). A resposta de voar da abelha identificada com tinta era modelada até que ela estivesse voando junto à caixa experimental. Nesse ponto, o pires era retirado e gotas do xarope eram depositadas diretamente sobre o tampo metálico da caixa. Depois que a abelha estivesse voando para a caixa de modo estável, o tampo era limpo nas suas bordas, e as gotas de xarope ficavam cada vez mais concentradas no centro desse tampo, junto aos orifícios por onde se tinha acesso ao xarope do reservatório, que ficava abaixo do tampo. Para atingir o xarope no reservatório, a abelha tinha que inserir a glossa em um dos orifícios. Posteriormente, o tampo da caixa experimental era completamente limpo e a abelha só conseguia xarope no reservatório. Uma ilustração dessa fase pode ser vista na Figura 1. Quando a resposta (voar até o aparelho, pousar e inserir a glossa no reservatório) estava modelada, a segunda caixa experimental era descoberta e as respostas passavam a ser reforçadas tanto em uma como em outra caixa. Os eventos compreendidos entre a saída da colméia, a resposta em uma das caixas experimentais e o retorno à colméia eram referidos pelo termo "visita". Esse período era bastante regular; raramente uma visita durava menos de um minuto ou mais de três minutos. Os intervalos entre visitas, também, mostraram-se bastante regulares, com duração aproximada de 1 minuto.

Estabelecimento de discriminaçôes condicionais - linha de base. Após o reforçamento de cerca de 10 visitas, os estímulos visuais eram sobrepostos aos aparelhos e tinha início diretamente o treino de discriminação condicional, 
primeiro em blocos com um mesmo modelo e, posteriormente, com a alternância rápida entre os modelos (conforme Pessotti, 1969, 1981). As lâmpadas eram empregadas como modelos e os discos coloridos eram empregados como estímulos de comparação, como mostrado no painel superior da Figura 2. Esse treino era conduzido em blocos de tentativas, definidos pelo tipo de alternância na seqüência de apresentações dos estímulos modelo, cuja descrição detalhada será feita a seguir.

A resposta de escolha era definida como o pouso sobre uma caixa experimental seguido da inserção da glossa no bebedouro. Em uma tentativa de treino, quando o sujeito emitia uma resposta na caixa experimental sinalizada com o estímulo definido como o comparação correto, o bebedouro ficava acessível ad libidum. Depois de sugar o xarope por aproximadamente $60 \mathrm{~s}$, a abelha voava de volta à colméia. Nesse momento, tinha início uma nova tentativa, com a disposição dos estímulos prevista para aquela tentativa. Ao sair da colméia, a abelha podia voar para a mesa onde estavam as caixas experimentais e emitir uma nova resposta. Se o sujeito emitia uma resposta na caixa experimental sinalizada com o comparação definido como incorreto, o xarope não era apresentado - a concha contendo xarope não era elevada até o bebedouro, então o sujeito podia voar para a outra caixa experimental, sinalizada com o comparação correto, onde tinha acesso livre ao bebedouro com xarope. Tão logo a abelha voasse de volta para a colméia, tinha início uma nova tentativa. Assim, o intervalo entre tentativas era definido pelo período em que a abelha estava no interior da colméia.

Alternância dos modelos após cada bloco de cinco visitas. Nas cinco tentativas iniciais, era apresentado apenas um dos modelos (duas lâmpadas acesas ou duas lâmpadas apagadas, uma sobre cada aparelho, A1 ou A2) e, simultaneamente, os dois comparaçóes, B1 e B2 (um disco amarelo e um disco azul), um em cada aparelho. Respostas ao comparação arbitrariamente definido como correto eram reforçadas e respostas ao comparação incorreto eram seguidas de extinçãa. A posição dos comparações (no aparelho "direito" ou no aparelho "esquerdo") era alternada randomicamente entre as tentativas. Para metade dos sujeitos, quando o modelo era luz acesa (A1), o comparação correto era o disco azul (B1) e quando o modelo era luz apagada (A2), o comparação correto era o disco amarelo (B2 - ver Figura 2, painel superior). Para os outros sujeitos, as contingências eram invertidas (luz acesa - disco amarelo, ou A1B2; luz apagada - disco azul, ou A2B1). Depois de cinco tentativas consecutivas, o primeiro modelo era substituído pelo segundo. Os modelos continuavam sendo alternados depois de cada cinco tentativas, até que fossem registradas 50 visitas, quando o bloco era encerrado, qualquer que fosse o desempenho das abelhas ao longo das 50 tentativas.

\section{Alternância dos modelos após cada bloco}

de duas visitas. Nesta fase os modelos passavam a ser alternados após cada duas visitas; duas tentativas com A1 como modelo eram seguidas por duas tentativas com A2 como modelo, repetidamente, até o critério. O bloco de tentativas era encerrado quando a proporção de acertos em um bloco de 10 visitas consecutivas era igual ou superior a $90 \%$. Enquanto o critério não fosse atingido, o sujeito continuava sendo exposto ao procedimento. Se a abelha interrompesse as visitas por mais de meia hora, a sessão era encerrada e reiniciada no dia se- 
guinte, com o procedimento que estava em vigor no encerramento da sessão prévia.

Alternância dos modelos em seqüência semialeatória. Quando o critério de pelo menos 90\% de acertos em 10 tentativas consecutivas era atingido na fase anterior, os modelos passavam a ser alternados em uma seqüência gerada por sorteio, visando aleatorizar, tanto quanto possível, os modelos e a posição dos estímulos de comparação, ao longo do bloco de tentativas. Procurava-se manter uma distribuição eqüitativa em termos de número de tentativas para o ensino de cada relação. Para a condução dos blocos de treino, o experimentador dispunha de um protocolo pré-programado, que indicava, para cada tentativa, qual deveria ser o estímulo modelo, qual a posição de cada um dos dois comparações e qual a resposta a ser reforçada. O bloco final de tentativas da linha de base era mantido até que se observasse um desempenho estável, definido por pelo menos $90 \%$ de acertos em um bloco com 10 tentativas consecutivas e com a exigência adicional de acerto na última tentativa do bloco. Enquanto esse duplo critério não fosse atingido, continuava em vigor o procedimento de linha de base.

Testes de simetria. Um teste de simetria consistia de seis tentativas de sonda (BA), conduzidas em extinção, distribuídas entre tentativas de linha de base (AB). Nas sondas, as funções dos estímulos modelo e de comparação eram revertidas: as cores passavam a ser empregadas como modelo e as lâmpadas passavam a ser empregadas como comparações (teste BA). Assim, para as abelhas que aprenderam as relações A1B1 e A2B2, o teste verificava se ocorriam as seleções de A1 diante de
B1 (B1A1) e de A2 diante de B2 (B2A2); para os demais sujeitos, as relações B1A2 e B2A1 (selecionar um estímulo A na presença de um estímulo B, de acordo com as relaçóes estabelecidas na linha de base) seriam indicadores da emergência de relações com a propriedade de simetria. Dada a natureza dos estímulos, sua apresentação era mantida na mesma localização e disposição presentes durante o treino, como mostra o painel inferior da Figura 2. O que era alterado era a forma de apresentação. Os dois discos de uma mesma cor ficavam dispostos sobre os aparelhos (o modelo), enquanto as lâmpadas, agora apresentadas como estímulos de comparação, eram apresentadas em estados diferentes, uma acesa e outra apagada.

Como as sondas de simetria eram conduzidas em extinção e isto poderia perturbar a linha de base, que continuava sendo mantida sob esquema de reforço contínuo, foi empregado um critério para apresentação das tentativas sucessivas de sonda, para evitar a apresentação de sondas depois de eventuais erros na linha de base; portanto, duas tentativas de sonda consecutivas eram intercaladas por pelo menos 10 tentativas de linha de base, desde que se observasse pelo menos $90 \%$ de acertos nesse conjunto de tentativas de linha de base e a última escolha antes da sonda tivesse sido correta. Para todos os sujeitos, três das sondas de simetria tinham a cor Azul (B1) como modelo e as outras três tinham a cor Amarela (B2) como modelo. A posição dos comparações (no aparelho "esquerdo" ou no aparelho "direito") era balanceada. O procedimento era encerrado depois da sexta sonda de simetria.

Observou-se que nas primeiras tentativas de sonda os sujeitos gastavam um longo tempo tentando alcançar o bebedouro ou sobrevo- 
ando os aparelhos, em movimentos diferentes do vôo direto observado nas tentativas de treino, o que aumentava o intervalo entre tentativas. Nas tentativas subseqüentes, porém, os sujeitos retornavam à colméia quase que imediatamente após encontrar os bebedouros sem acesso ao xarope.

\section{RESULTADOS}

\section{Aquisição da linha de base}

As discriminações condicionais foram aprendidas por todos os sujeitos, embora o número de tentativas necessárias para o estabelecimento das discriminações tenha variado consideravelmente entre os sujeitos. A Figura 3 apresenta curvas de freqüência acumulada de respostas de seleção do $S_{+}$(respostas discrimi-
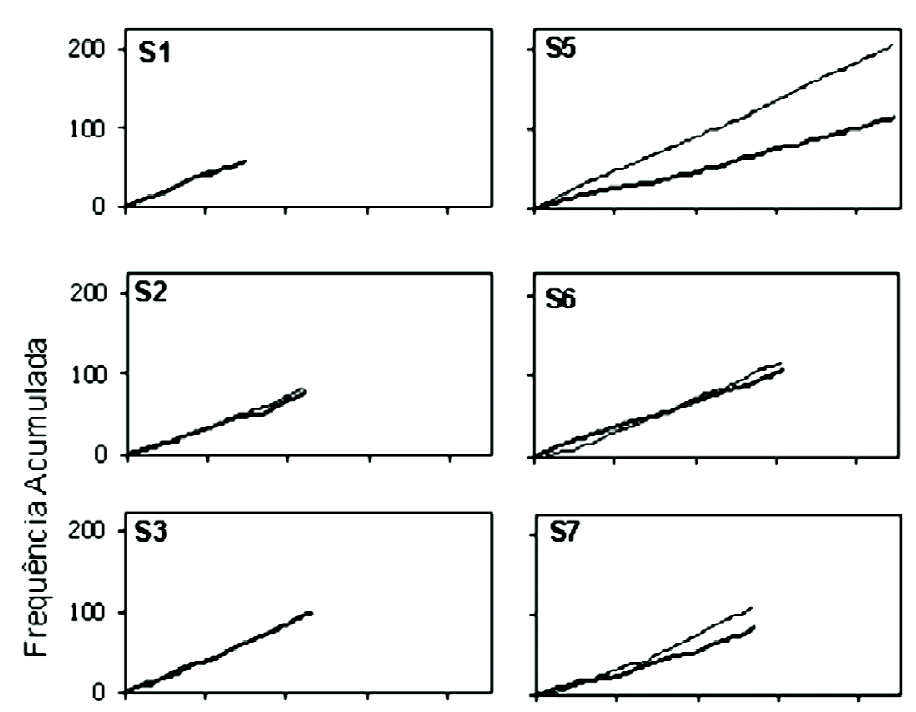
esquerda), durante todo o treino, a proporção de respostas corretas ao Azul (quando o modelo era lâmpada acesa) praticamente coincidiu com a proporção de respostas corretas ao disco Amarelo (lâmpada apagada como modelo). Estas abelhas apresentaram poucos erros e atingiram o critério com um número de tentativas que variou entre $70(\mathrm{~S} 3)$ a 100 (S2). As abelhas na coluna direita apresentaram curvas acumuladas discrepantes entre os dois compara-

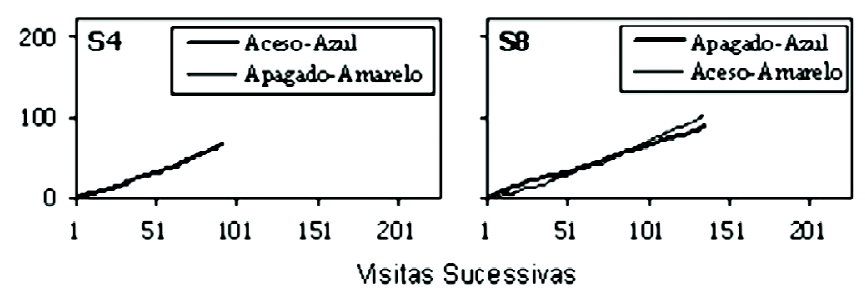

Figura 3 - Freqüência acumulada de respostas discriminadas (corretas) na presença do modelo lâmpada acesa e do modelo lâmpada apagada ao longo da seqüência de treino. 
ções, assim como diferenças grandes quanto ao número de tentativas para atingir o critério de aquisição (de 100 tentativas para a abelha S6 até 240 tentativas para a abelha S5). Para a abelha $S 5$, a proporção de respostas corretas ao comparação Amarelo (na presença de lâmpada acesa) foi consideravelmente maior que a proporção de respostas corretas ao comparação Azul. Ao final do treino, as abelhas S6, S7 e S8 também apresentaram a proporção de respostas corretas ao Amarelo maior do que a proporção de acertos ao Azul.

\section{Testes de simetria}

Os resultados das sondas de simetria são apresentados nas Figuras 4 e 5. Em ambas as figuras os resultados das sondas são apresentados juntamente com os desempenhos na linha de base, mas enquanto a Figura 4 apresenta dados agregados para os dois pares de estímulos, na Figura 5 são apresentadas as distribuições de respostas a cada estímulo de comparação correto.

Na Figura 4, as barras brancas representam a porcentagem de acertos na linha de base estável ao final da fase de treino (no bloco de 10 tentativas que precedeu o bloco de testes), denominada, por conveniência de expressão, Linha de Base Pré-Teste; as barras cinzas representam a porcentagem de acertos nas tentativas de linha de base intercaladas com as tentativas de sondas, no bloco de testes; e as barras pretas representam o desempenho nas sondas de simetria, em termos de porcentagem de respostas consistentes com uma relação simétrica das relaçôes definidas pelas contingências experimentais. Quanto à linha de base que precedeu imediatamente os testes, as abelhas S3 a S8 apresentaram porcentagens iguais ou superiores a $90 \%$, sendo que três delas (S3, S6 e S8) acertaram $100 \%$ das tentativas. As abelhas S1 e S2 apresentaram $80 \%$ de acertos, porcentagem considerada abaixo do critério, mas ainda assim foram expostas ao bloco de testes; isto se deveu ao fato de que o critério foi refinado depois da coleta com essas duas abelhas. Nas sondas de simetria, como mostram as barras pretas, duas abelhas (S4 e S7) apresentaram respostas consistentes com a propriedade de simetria em todas as seis tentativas e quatro abelhas (S1, S2, S3 e S8) apresentaram desempenho consistente em 5 das seis tentativas; estas seis abelhas atingiram o critério para definição do responder emergente (pelo me-

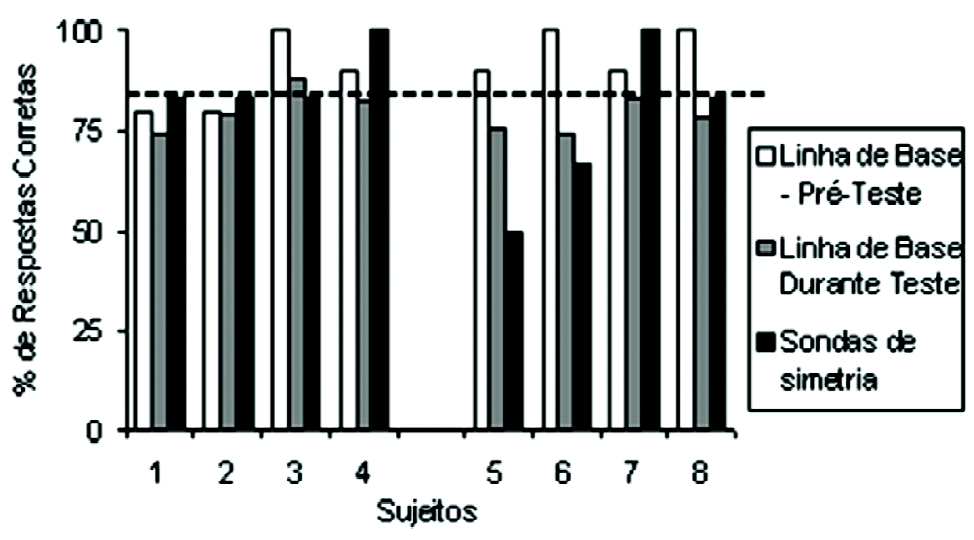

Figura 4 - Porcentagem de respostas corretas na linha de base (antes e durante o teste de simetria) e porcentagem de respostas consistentes com a linha de base nas sondas de simetria. 
nos cinco em seis tentativas ou porcentagem maior ou igual a 83,3\%). Duas abelhas apresentaram desempenho abaixo desse critério, uma com duas respostas inconsistentes (S6) e uma com a metade das respostas inconsistentes (S5). Nota-se que, em geral, ocorreu uma redução na porcentagem de acertos nas tentativas de linha de base intercaladas com as sondas de simetria (barras cinzas), quando comparada à linha de base prévia, e essa perda foi mais acentuada para as abelhas S5 (com 75,5\% de acertos) e S6 (com 74,2\%), as mesmas abelhas que não atingiram o critério de simetria emergente, assim como para a abelha $S 1$, que apresentou um desempenho de 73,9\% de acertos nessas tentativas de linha de base intercaladas com sondas de simetria (enquanto apresentou $83,3 \%$ de respostas consistentes nas sondas). Ainda assim, as porcentagens de acertos na linha de base mantiveram-se acima de $70 \%$ para todas as abelhas (variação entre $73,9 \%$ e $87,6 \%)$.

A Figura 5 permite uma análise mais detalhada dos dados, mostrando a distribuição percentual de respostas corretas na presença de cada um dos dois comparaçôes na linha de base e nas sondas de simetria. A linha de base foi separada em linha de base prévia, linha de base imediatamente antes do teste (pré-teste) e linha de base durante o teste. No primeiro caso, a porcentagem foi calculada sobre o total de tentativas desde o início do estabelecimento das discriminações condicionais. No pré-teste, calculou-se a porcentagem de acertos no bloco de 10 tentativas que precedeu imediatamente o bloco de testes. E durante o teste, calculouse a porcentagem de acertos sobre o total de tentativas de linha de base que se alternaram com as de sonda. O número de tentativas (n) está indicado acima de cada medida. Cada barra representa a porcentagem de respostas corretas na presença de um determinado estímulo de comparação (o máximo era 50\%, uma vez que cada estímulo era o $S+$ em metade das tentativas). O número de tentativas de sondas de simetria era seis, três para cada par de estímulos.

Considerando o balanceamento entre sujeitos, os dados foram distribuídos em duas colunas. Na coluna da esquerda são apresentados os dados do sujeitos que aprenderam as relaçôes A1B1 e A2B2 (a lâmpada acesa como estímulo condicional para a seleção do disco azul e a lâmpada apagada como estímulo condicional para selecionar o disco amarelo). $\mathrm{Na}$ coluna da direita encontram-se os dados dos sujeitos que aprenderam as relações A1B2 (lâmpada acesa - disco amarelo) e A2B1 (lâmpada apagada- disco azul).

Observa-se, na coluna da esquerda, e especialmente na Linha de Base Pré-Teste, que os sujeitos apresentaram percentagens bem maiores de respostas discriminadas do que de respostas ao S- e que as percentagens de acertos e erros se distribuíram sem muitas discrepâncias na presença de um e de outro modelo, isto é, as abelhas aprenderam a selecionar consistentemente o disco azul na presença da lâmpada acesa (barras pretas); aprenderam também a selecionar o disco amarelo se a lâmpada estivesse apagada (barras cinzas). Assim, a probabilidade de respostas corretas ao estímulo B1 (respostas discriminadas) na presença do estímulo condicional $\mathrm{A} 1$ foi semelhante à probabilidade de respostas corretas ao estímulo B2 na presença do estímulo condicional $\mathrm{A} 2$, ao longo da aquisição das discriminações condicionais e se manteve assim, mesmo durante o bloco de testes. Nas sondas de simetria, as 
quatro abelhas nesta condição atingiram o critério de respostas consistentes com a linha de base, considerando-se que as três primeiras apresentaram apenas uma resposta inconsistente e a quarta apresentou $100 \%$ de respostas consistentes com a propriedade simétrica às relações ensinadas na linha de base. Nota-se, no entanto, que a resposta inconsistente das três primeiras abelhas consistiu na seleção da lâmpada apagada, quando o modelo era constituído pelos dois discos azuis (selecionaram A2 na presença de B1).

Os sujeitos para os quais as contingências eram inversas apresentaram desempenhos diferentes na aquisição das duas relações, como mostram as barras na coluna da direita na Figura 5. Na linha de base prévia, duas abelhas (S6 e S8) apresentaram discriminações mais
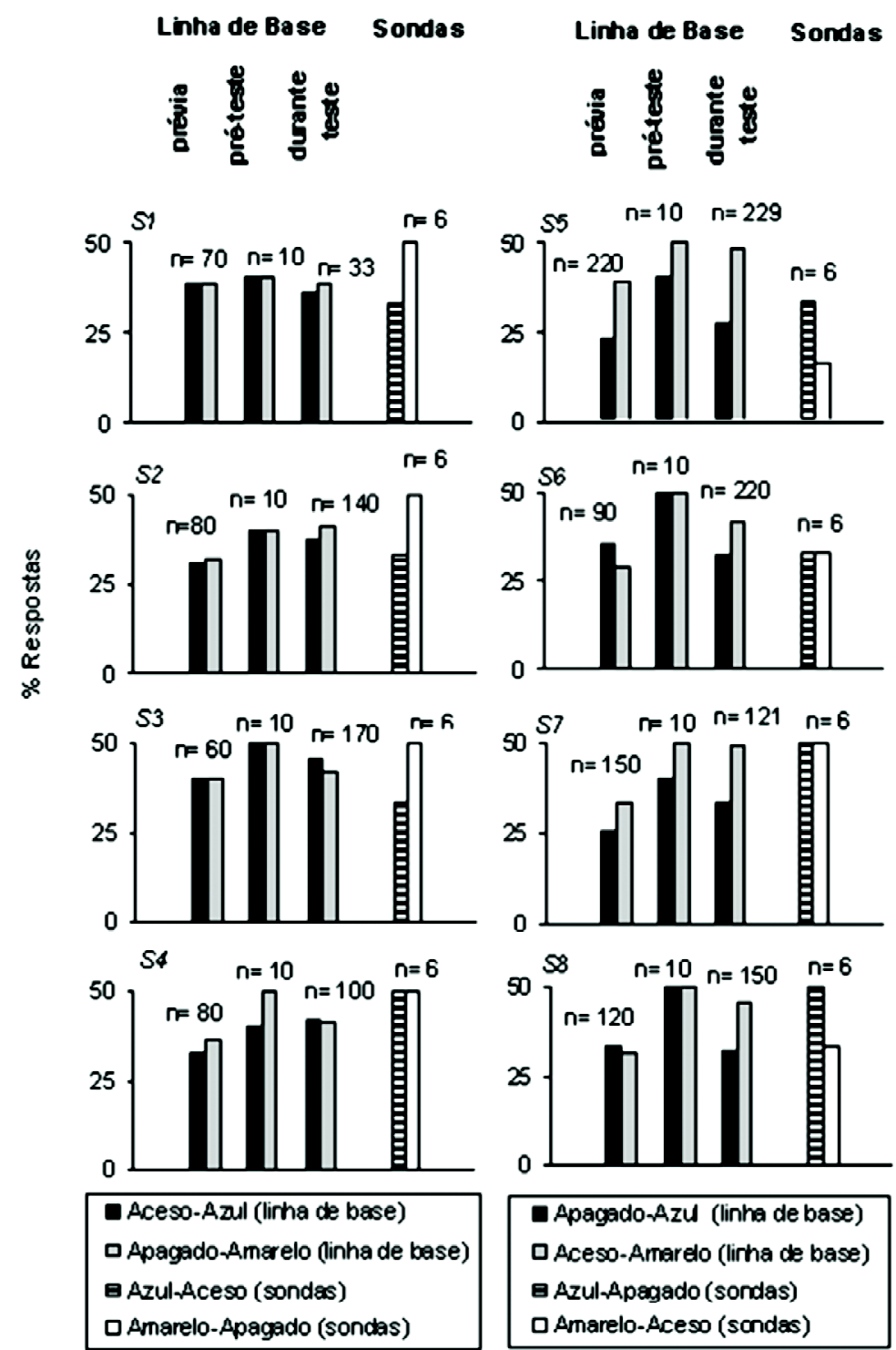

Apagado-Azu (linha de base)
$\square$ Aceso-Amarelo (lirha de base)
a Azul-Apagado (sondas)
$\square$ Amarelo-Aceso (sondas)

Figura 5 - Distribuição de respostas em porcentagem durante estabelecimento de discriminações condicionais e durante teste de simetria, organizada em Linha de Base Prévia, Linha de Base Pré-Teste, Linha de Base Durante Teste e Sondas. O índice n indica o número de respostas para cada fase. 
refinadas (mais respostas ao $S_{+}$do que ao $S$-) na presença do modelo lâmpadas apagadas (selecionando o disco azul), enquanto a porcentagem de erros foi apenas ligeiramente inferior à porcentagem de acertos para a abelha $S 7$, e chegou mesmo a ser maior que a de acertos para a abelha S5, que requereu muitas tentativas até atingir o critério. No entanto, no bloco final de linha de base antes do teste (Linha de Base Pré-Teste), as quatro abelhas estavam apresentando responder aparentemente sob controle condicional (S5 e S7 erraram uma tentativa com o modelo luzes apagadas). Nas sondas de simetria, duas das abelhas, S5 e S6, não atingiram o critério de emergência de relaçôes simétricas. S5 apresentou metade das respostas consistentes com a linha de base e S6 apresentou quatro respostas consistentes. A abelha 5 também apresentou evidente deterioração da linha de base na presença das lâmpadas apagadas como modelo (portanto escolhia o amarelo quer as luzes estivessem apagadas, quer estivessem acesas). Observa-se que as outras três abelhas representadas na coluna direita da Figura 5 também apresentaram desempenho na presença do modelo lâmpada acesa bastante superior ao desempenho na presença do modelo lâmpada apagada. As abelhas S7 e S8, contudo, apresentaram responder consistente com a emergência de simetria (zero e um erro, respectivamente) e mantiveram a linha de base discriminada, a despeito da ocorrência de erros nas tentativas de linha de base.

\section{DISCUSSÃO}

Os resultados da fase de estabelecimento de discriminações condicionais evidenciaram que as abelhas apresentaram aprendizagem relacional, replicando e estendendo as desco- bertas de Pessotti $(1969,1981)$ e de Giurfa et al. (2001).

A demonstração de relações condicionais em animais dessa espécie, por si só, atesta a relevância do estudo, a despeito de limitaçôes decorrentes do tipo de equipamentos empregados, tanto do ponto de vista do operante empregado, quanto da aplicação do procedimento e registro dos dados. A resposta definida como operante apresenta ambigüidades. A inserção da glossa no bebedouro, definida como a resposta operante, não era registrada mecanicamente ou de modo eletrônico; era registrada pelo experimentador. Em seguida à observação dessa resposta, o reforço era apresentado por meio da operação manual do bebedouro. Portanto, a apresentação do reforço podia não se seguir imediatamente à resposta, o que podia acarretar efeitos de atraso de reforço. Ainda, por falha do experimentador, uma resposta definida como correta podia não ser reforçada, ou uma resposta definida como incorreta podia ser indevidamente reforçada. A resposta também não produzia uma mudança saliente no ambiente (por exemplo, um estímulo sonoro) que servisse como feedback para facilitar o estabelecimento do operante. Apesar disso, as curvas de discriminação resultantes evidenciam que mesmo com essas eventuais dificuldades, o repertório de discriminações foi bem estabelecido.

Um segundo achado importante do estudo foram os desempenhos nos testes de simetria, que demonstraram que essa relação emergiu para seis dos oito sujeitos (mas uma interpretação alternativa para esses resultados será discutida mais adiante). Se puderem, de fato, ser tomadas como relações simétricas, então esses dados confirmam e estendem para meliponas aqueles encontrados para leões ma- 
rinhos (Shusterman \& Kastak, 1993), periquitos (Manabe, Kawashima, \& Staddon, 1995) e macacos-prego (Barros \& Galvão, 2003). Contribui assim, com a corrente da literatura que sugere que a demonstração de relações emergentes em infra-humanos pode ser uma questão de procedimento, mais que uma questão relacionada a características da espécie estudada (Dube, McIlvane, Callahan \& Stoddard, 1993). Apesar das dificuldades operacionais descritas para o estabelecimento da linha de base, as contingências de reforço programadas neste estudo incorporaram os desenvolvimentos técnicos mais recentes, os quais têm sido importantes no estabelecimento de discriminações simples e condicionais.

Alguns aspectos dos resultados merecem uma consideração mais detalhada.

O emprego de condições balanceadas quanto aos pares de estímulo empregados como modelos e comparações evidenciaram a ocorrência de diferenças nos desempenhos dos sujeitos expostos a cada condição. Enquanto todos os sujeitos que aprenderam as relações lâmpada acesa - disco azul e lâmpada apagada - disco amarelo (S1, S2, S3 e S4) apresentaram discriminações mais acuradas e demonstraram simetria, apenas dois entre os quatro outros sujeitos que aprenderam as relações lâmpada acesa - disco amarelo e lâmpada apagada - disco azul, demonstraram relações simétricas, depois de terem apresentado muitos erros na fase de aquisição (linha de base menos acurada). De modo consistente, os sujeitos S1, S2, S3 e S4 adquiriram as discriminaçôes condicionais com menos treino do que os sujeitos S5, S6, S7 e S8.

Os sujeitos que foram treinados a responder às relaçôes lâmpada acesa - disco amarelo e lâmpada apagada - disco azul (S5, S6, S7 e S8) apresentaram melhor desempenho na presença do modelo lâmpada acesa do que na presença do modelo lâmpada apagada. Nas tentativas de linha de base que intercalaram as tentativas de sonda, a porcentagem de erros na presença do modelo lâmpada apagada variou entre $31,4 \%$ (S7) e $44,4 \%$ (S5), enquanto a porcentagem de erros na presença do modelo lâmpada acesa variou entre apenas 1,6\% (S7) até $17,8 \%$ (S6). Essa diferença de desempenho na presença de um e outro modelo, com a implicação de um controle condicional impreciso (ou ausência de controle condicional), sugere a possível atuação de variáveis não controladas, entre elas o fato de que as abelhas, em geral, voam na direção da luz (Pessotti, 1969). Nesse caso, haveria uma possível interação entre o controle exercido por um estímulo possivelmente eliciador e o controle discriminativo, uma vez que esse mesmo estímulo poderia estar correlacionado tanto ao $S+$ (efeitos somados), como ao $S$ - (efeitos competitivos).

Outra interpretação para os diferentes graus de acurácia diante de diferentes configuraçôes para os mesmos quatro estímulos (presença ou ausência de luz e cor amarela ou azul) pode ser formulada com base no conceito de topografias de controle de estímulos (Barros, Galvão, Brino, Goulart, \& Mcllvane, 2005; Dube \& McIlvane, 1996; Ray, 1969), segundo o qual, o controle de estímulos sobre o responder pode ser decomposto em diferentes topografias de controle de estímulos, engendradas pelas contingências. Como cada estímulo tem múltiplas propriedades, embora o experimentador defina que a conseqüência será contingente a uma delas, não há como impedir que outra esteja presente no momento do reforço e assuma controle sobre o responder. Por exemplo, quando voa na direção do disco 
azul, a abelha pode também estar voando na direção do estímulo que está localizado à esquerda; cor e posição são duas propriedades do mesmo estímulo e a conseqüência tanto pode fortalecer o controle pela cor, como pela posição. Do mesmo modo, em uma discriminação condicional a escolha de um estímulo de comparação pode ocorrer sob controle de uma relação entre aquele estímulo e o estímulo modelo (controle por seleção) ou por uma relação entre o modelo e o outro comparação (controle por rejeição), como apontado por Johnson e Sidman (1993). Precisão intermediária pode ser produto de controles múltiplos como esses (Dube \& Mcllvane, 1996). No presente estudo, o desempenho da abelha S5 fornece um exemplo: nas tentativas de linha de base durante o teste de simetria a porcentagem total de acertos foi 75,5\% (Figura 4), mas quando as escolhas foram analisadas separadamente (Figura 5), pode-se notar que ela escolheu sistematicamente a cor amarela na presença da luz acesa (96\% de acertos); porém, quando a lâmpada estava apagada, ela escolhia ora o azul, ora o amarelo (apenas $55 \%$ de acertos); desse modo, não se pode dizer que a escolha do amarelo estivesse exclusivamente sob controle da lâmpada acesa (já que a mesma escolha ocorria também diante da lâmpada apagada). O procedimento não permite identificar qual seria a topografia de controle prevalente (posição, cor, combinação luminosidade - cor amarela?), mas os dados apontam que havia topografias diferentes concorrendo pelo controle das respostas. Ou seja, o primeiro desempenho parece coerente com a contingência definida pelo experimentador, conforme a teoria da coerência de topografias de controle de estímulos (Mcllvane, Serna, Dube, \& Stromer, 2000), enquanto o segundo desempenho pro- vavelmente esteve sob controle de outra contingência, não prevista.

Com o procedimento deste estudo, em que não era possível apresentar os estímulos luminosos nas mesmas localizações que os coloridos e vice-versa, diferentes tipos de resultados poderiam ser esperados nos testes de simetria, entre eles uma deterioração do desempenho em relação à linha de base. A deterioração poderia ocorrer se o treino tivesse produzido apenas controle por quatro configurações de estímulos. Esse controle, então, seria incompatível com a situação de teste, na qual "configuraçōes inéditas" seriam apresentadas. Esse tipo de interpretação é encontrado no estudo de Kamil e Sacks (1972), em que a configuração "nova" produziu acurácia ao nível do acaso. No presente estudo, todas as configurações de estímulo (tomadas como o conjunto de luzes e cores simultaneamente presentes nas duas caixas) apresentadas durante os testes de simetria eram "novas", no sentido empregado por aqueles autores (ver Figura 2), isto é, como configuração não teriam sido apresentadas no treino.

A definição de simetria proposta por Sidman e Tailby (1982) nada estabelece além da reversão das funções dos estímulos modelo e de comparação. No estudo de Lipkens et al. (1988), o teste de simetria não previa a troca de posições entre os estímulos modelo e os comparações; tal como no presente estudo, apenas as funções foram revertidas, contudo os resultados nos testes foram negativos. Entretanto, nesses dois estudos, nenhum tipo de resultado poderia "acusar" controle por localização, tal como no experimento de Iversen et al. (1986), no qual a situação de teste de simetria apresentava algumas configurações de estímulo idênticas a configuraçôes apresentadas no 
treino, mas também apresentava uma configuração inédita. No estudo de Iversen et al. (1986), mesmo as configurações "velhas" levaram a desempenhos de teste inferiores aos de linha de base. Por esses estudos, seria possível prever que a mudança das funções dos estímulos no teste de simetria, por si só, seria suficiente para determinar desempenhos inferiores nos testes, o que não foi observado neste estudo. Aqui, observou-se que o desempenho tendia a se deteriorar depois de cada sonda de simetria (conduzida em extinção), nas tentativas de linha de base que se seguiam, mas o desempenho nas sondas não se deteriorava significativamente (ver Figuras 4 e 5). Assim, o fato de não ter sido observada, para todos os sujeitos, uma descontinuidade significativa entre $o$ desempenho de linha de base e o desempenho nos testes favorece a hipótese de emergência de relações simétricas.

Contudo, uma hipótese alternativa é a de que os resultados positivos obtidos nos testes do presente estudo poderiam ter resultado do desenvolvimento de controle discriminativo por estímulos compostos (luz+cor). Neste caso, durante o treino os sujeitos teriam discriminado, em vez de quatro configuraçoóes de estímulo, configurações de dois pares de estímulos compostos. Por exemplo, em uma tentativa de treino em que as duas lâmpadas acesas foram definidas como o estímulo modelo e os discos azul e amarelo foram definidos como os comparações, o sujeito estaria respondendo aos estímulos compostos "lâmpada acesa - disco azul" (como $S_{+}$) e "lâmpada acesa - disco amarelo" (como S-). Inversamente, em tentativas com o outro modelo (as duas lâmpadas apagadas), o sujeito estaria respondendo aos estímulos compostos "lâmpada apagada - disco amarelo" (como S+) e "lâmpada apagada - disco azul" (como S-). Então, em uma sonda de simetria em que dois discos azuis foram definidos como o modelo, e uma lâmpada acesa e outra apagada foram definidas como os estímulos de comparação, o sujeito poderia responder, do mesmo modo, ao estímulo composto "lâmpada acesa - disco azul" (um dos $\left.S_{+}\right)$e rejeitar o estímulo composto "lâmpada apagada - disco azul" (um dos S-) ao qual também foi exposto durante o treino. Poderia ocorrer, assim, que o sujeito tivesse aprendido a responder ao composto lâmpada acesa azul, ou lâmpada apagada - amarelo, independentemente do que fosse apresentado como o outro membro do par. O painel inferior da Figura 2 mostra claramente essa possibilidade. Nesse caso, os dados do presente estudo seriam evidências insuficientes de discriminação condicional e de propriedades simétricas dessas relações.

A hipótese de que nos resultados deste estudo, assim como nos de alguns outros, desempenhos em discriminação condicional ou em simetria poderiam consistir, de fato, em discriminações simples (entre estímulos compostos) possivelmente seria afastada apenas se fossem obtidos desempenhos mais complexos, como a emergência de relações de transitividade (em que são apresentados simultaneamente estímulos que nunca ocorreram juntos antes), ou quando se empregam técnicas apropriadas para a identificação das relações de controle na linha de base, como por exemplo, o uso de estímulos novos ou o emprego do comparação vazio (Mcllvane et al., 1987; Wilkinson \& McIlvane, 1997).

Estas possibilidades deverão ser investigadas empiricamente, sendo os dados interpretados com cautela, tendo em vista que nenhum procedimento nessa área de estudos 
até o momento respondeu a todas as perguntas pertinentes, e isso determina que se adote um comportamento analítico ao ponto de propor procedimentos imediatamente derivados dos estudos correntes, com vistas à dissolução de um primeiro conjunto de ambigüidades, sabendo-se que o novo conjunto de dados requererá novos estudos para clarificação em relação a um novo conjunto de ambigüidades.

Por exemplo, mesmo um desempenho de transitividade não pode ser imediatamente interpretado como uma evidência de relação de equivalência. Uma relação condicional desse tipo poderia derivar de controle de estímulos negativos (Johnson \& Sidman, 1993; Lipkens, 1988). Sidman (1987) propôs que essa dificuldade deveria ser superada empregando-se ao menos três estímulos de comparação.

Em estudos prévios realizados neste laboratório, foram obtidas discriminações acuradas utilizando-se como estímulos superfícies de cor azul, amarela, branca ou preta e lâmpadas de cor azul e lâmpadas de cor amarela. Também foram estabelecidas discriminações entre lâmpada acesa e lâmpada apagada. Esses achados sustentaram a construção de equipamentos com controle eletrônicos, a serem empregados em novos estudos, com os quais será possível requerer um operante melhor definido (pressionar uma barra) e empregar uma variedade maior de estímulos luminosos, cujas posições poderão ser variadas.

Considerando-se a possibilidade de controle por estímulo composto no presente estudo, o novo equipamento permitiria a implementação de procedimentos para clarificar essa ambigüidade, como por exemplo, o uso de luzes coloridas tanto quanto estímulo condicional, quanto como discriminativo em um protocolo de treino $\mathrm{AB} / \mathrm{AC}$ ou $\mathrm{AB} / \mathrm{BC}$, onde seis diferentes cores seriam usadas, com condução de testes de simetria, transitividade e simetria da transitividade.

Nos estudos que utilizaram o procedimento de matching-to-sample, tornou-se comum o emprego de estímulos visuais que eram apresentados como figuras - uma determinada forma (triângulo, círculo etc), uma superfície de uma única cor (vermelho, verde) ou um padrão visual (listras verticais, listras horizontais etc). Os estímulos são definidos em uma área limitada, geralmente um plano, e, como figuras, todos têm o mesmo "tamanho". Assim, é possível garantir que, espacialmente, esses estímulos são, de fato, independentes: pode-se organizar os estímulos em configurações variadas. Por exemplo, o modelo e os dois comparações podem ocupar posiçôes aleatórias em um painel com nove posições (em forma de matriz 3 X 3). Se o sujeito apresenta um desempenho positivo em um teste em que os estímulos foram arranjados em uma configuração inédita, pode-se afirmar com alguma segurança que essa generalização foi abstraída da localização desses estímulos (Barros \& Galvão, 2003; Iversen \& Sidman, 1986). Essas características de procedimento deverão ser levadas em consideração no planejamento para estudos de aprendizagem relacional em abelhas, que deverão eliminar uma particularidade indesejável do procedimento do presente estudo, relativa à posição do operandum. Enquanto em um procedimento de emparelhamento com o modelo típico as respostas rastreiam os estímulos (observação ao modelo e seleção do comparação), no procedimento deste estudo, as respostas sempre ocorriam junto a um dos discos de material emborrachado; não havia respostas "junto às lâmpadas". Essa característica pode ser tomada como uma limitação experimental 
que torna mais difícil interpretar o desempenho do sujeito como uma discriminação condicional "verdadeira", uma vez que não era possível intercambiar a posição do modelo e dos comparações. Ou então, essa característica poderia ser interpretada apenas como um fator que dificultava a aprendizagem, por tornar menos saliente um estímulo definido pelo estado (lâmpada acesa / lâmpada apagada) de uma ou ambas as lâmpadas. O estudo de Pessotti (1969) e estudos previamente conduzidos neste laboratório (não publicados) sugerem que os estímulos utilizados em tarefas de aprendizagem para abelhas devem estar próximos ao local onde as abelhas respondem e ao bebedouro, onde coletam o xarope. Essa especificidade do treino com abelhas requer cuidados especiais na apresentação de estímulos em várias posições.

Sob as condiçõos do presente experimento, não se pode afirmar com segurança que os seis sujeitos que atingiram o critério apresentaram nem que não apresentaram simetria. Estudos subseqüentes devem incluir procedimentos especialmente planejados para permitir a identificação das relações de controle engendradas pelas contingências experimentais. Só com esse tipo de recurso seria possível ir além da sugestão de que a relação de simetria pode emergir de discriminaçōes condicionais estabelecidas em abelhas. Os resultados produzidos até o presente são promissores, no sentido de que evidenciaram que o laboratório dispõe de condições e procedimentos que tornam viável replicar os procedimentos operantes pioneiros desenvolvidos por Pessotti, mas apontam também que é imperativo desenvolver equipamentos apropriados, com controle automático e flexibilidade na apresentação de estímulos, para que se possa realizar novas investigações e facilitar a interpretação de dados sobre desempenhos de abelhas em testes de propriedades emergentes, como a simetria, a transitividade e mesmo a equivalência, a partir de procedimentos de emparelhamento com o modelo.

\section{REFERÊNCIAS}

Barros, R. S., \& Galvão, O. F. (2003). Aprendizagem relacional com posições como estímulo em macacos-prego (Cebus apella). Acta Comportamentalia, 11(1), 47-85.

Barros, R. S., Galvão, O. F., \& McIlvane, W. V. (2002). Generalized identity matching-to-sample in Cebus apella. The Psychological Record, 52, 441-460.

Barros, R. S., Galvão, O. F., \& McIlvane, W. J. (2003). The search for relational learning capacity in Cebus Apella: A programmed "educational" approach. In S. Soraci Jr., \& K. Murata-Soraci (Eds.) Visual Information Processing, Westport, CT: Praeger.

Barros, R. S., Galvão, O. F., Brino, A. L. F., Goulart, P. R. K., \& McIlvane, W. J. (2005). Variáveis de procedimento na pesquisa sobre classes de equivalência: contribuições para o estudo do comportamento simbólico. Revista Brasileira de Análise do Comportamento, 1, 15-27.

Berryman, R., Cumming, W. W., Cohen, L.R., \& Johnson (1965). Acquisition and transfer of simultaneous oddity. Psychological Report, 17, 767775.

Catania, A. C. (1999). Aprendizagem: Comportamento, Linguagem e Cognição. Porto Alegre: Artmed.

Cumming, W. W., \& Berryman, R. (1961). Some data on matching behavior processing by pigeons: A critical analysis. Journal of the Experimental Analysis of Behavior, 4, 281-284.

Cumming, W. W., \& Berryman, R. (1965). The complex discriminated operant: Studies of matching to sample and related problems. In D. I. Mostofski 
(Ed.). Stimulus generalization. Standford, CA: Standford University Press.

de Rose, J. C. (1993). Classes de estímulos: implicaçōes para uma análise comportamental da cognição. Psicologia: Teoria e Pesquisa, 9(2), 283-303.

Dube, W. V., \& McIlvane, W. J. (1996). Some implications of a stimulus control topography analysis for emergent stimulus classes. In T. R. Zentall \& P. M. Smeets (Orgs.), Stimulus class formation in humans and animals (pp. 197-218). North Holland: Elsevier.

Dube, W. V., \& McIlvane, W. J. Callahan, T. D., \& Stoddard, L. T. (1993). The search for stimulus equivalence in nonverbal organisms. The Phsychological Record, 43, 761-778.

Dugdale, N., \& Lowe, C. F. (1990). Naming and stimulus equivalence. In D. Blackman \& H. Lejeune (Eds.), Behavior analysis in theory and practice (pp. 115-138). Hillsdale, NJ: Erlbaum.

Giurfa, M., Zhang, S., Jenett, A., Menzel, R., \& Srinivasan, M. V. (2001). The concepts of 'sameness' and 'difference' in an insect. Nature, 410, 930-932.

Hayes, S. C. (1989). Nonhumans have not yet shown stimulus equivalence. Journal of the Experimental Analysis of Behavior, 51, 385-392.

Iversen, I. H., Sidman, M., \& Carrigan, P. (1986). Stimulus definition in conditional discrimination. Journal of the Experimental Analysis of Behavior, 45, 297-304.

Johnson, C., \& Sidman, M. (1993). Conditional discrimination and equivalence relations: Control by negative stimuli. Journal of the Experimental Analysis of Behavior, 59, 333-347.

Kamil, A. C., \& Sacks, R. A. (1972). Threeconfiguration matching-to-sample in the pigeons. Journal of the Experimental Analysis of Behavior, 17, 483-488.

Lionello, K. M., \& Urcuioli, P. J. (2002). Transfer of pigeons' matching to sample to novel sample locations. Journal of the Experimental Analysis of Behavior, 73, 141-161.

Lipkens, R., Kop, P. F. M., \& Matthijs, W. (1988). A test of symmetry and transitivity in the conditional discrimination of pigeons. Journal of the Experimental Analysis of Behavior, 49, 395-409.

Manabe, K., Kawashima, T., \& Staddon, J. E. R. (1995). Differential vocalization in budgerigars: Towards an experimental analysis of naming. Journal of the Experimental Analysis of Behavior, 63, 111-126.

McIlvane, W. J., Kledaras, J. B., Munson, L. C., King, K. A., de Rose, J. C., \& Stoddard, L. T. (1987). Controlling relations in conditional discrimination and matching by exclusion. Journal of the Experimental Analysis of Behavior, 48, 187-208.

McIlvane, W.J., Serna, R. W., Dube, W. V., \& Stromer, R. L. (2000). Stimulus control topography coherence and stimulus equivalence: Reconciling test outcomes with theory. Em J. Leslie \& D. E. Blackman (Eds.). Experimental and applied analysis of human behavior, (pp. 85-110). Reno, NV: Context Press.

McIntire, K. D., Cleary, J., \& Thompson, T. (1987). Conditional relations by monkeys: Reflexivity, symmetry, and transitivity. Journal of the Experimental Analysis of Behavior, 47, 279-285.

Michael, J. (1982). Distinguishing between discriminative and motivational functions of stimuli. Journal of the Experimental Analysis of Behavior, 37, 149-155.

Pessotti, I. (1964). Estudo sobre aprendizagem e extinção em Apis mellifera. Jornal Brasileiro de Psicologia, 1 (2), 97-100.

Pessotti, I. (1965). Condicionamento de respostas sob diferentes razões fixas sucessivas em Melipona seminigra merrilae. Jornal Brasileiro de Psicologia, 1 (1), 11-25.

Pessotti, I. (1967a). Algumas medidas de aprendizagem e extinção de uma discriminação em duas espécies de abelhas sociais. Revista de Psicologia Normale Patológica, 1 e 2, 51-60. 
Pessotti, I (1967b). Aprendizagem de discriminação como um critério de classificação de abelhas. Revista Interamericana de Psicologia, 1 (3), 177-187.

Pessotti, I. (1969). Discriminação em Melipona (Micherenia) rufiventris Lepertier. Tese de Doutorado. Departamento de Psicologia Social e Experimental da Faculdade de Filosofia, Ciências e Letras da Universidade de São Paulo. São Paulo.

Pessotti, I. (1971a). Come apprendono le api. Le Scienze [edizione italiana di Scientific American], 6 (33), 11-21.

Pessotti, I. (1971b). Discrimination with light stimuli and lever-pressing response in Melipona rufiventris. Journal of Apicultural Research, 11 (2), 89-93.

Pessotti, I. (1981). Aprendizagem em abelhas. VI - Discriminação condicional em Melipona rufiventris. Revista Brasileira de Psicologia, 41 (4), 681-693.

Pessotti, I, \& Lé Senechal, A.M. (1981). Aprendizagem em abelhas. I - Discriminação simples em 11 espécies. Acta Amazonica, 11 (3), 653-658.

Pessotti, I., \& Otero, V. R. L. (1981). Aprendizagem em abelhas. IV: Punição e resistência à extinção. Revista Brasileira de Psicologia, 41 (4), 673-680.

Ray, B. (1969). Selective attention: The effects of combining the stimuli, wich control incompatible behavior. Journal of the Experimental Analysis of Behavior, 12, 539-550.

Schusterman, R. J., \& Kastak, D. (1993). A California sea lion (Zalophus califonianus) is capable of forming equivalence relations. The Psychological Record, 43, 823-839.

Sidman, M., (1987). Two choices are not enough. Behavior Analysis, 22, 11-18.
Sidman, M., (1994). Equivalence relations and behavior: A research story. Boston: Authors Cooperative.

Sidman, M., \& Tailby, W. (1982). Conditional discrimination $v$ s. matching to sample: An expansion of the testing paradigm. Journal of the Experimental Analysis of Behavior, 37, 5-22.

Thomas, D. R., Stengel, T., Sherman, L., \& Woodford, M. (1987). Factors affecting conditional discrimination learning by pigeons. Journal of the Experimental Analysis of Behavior, 48, 277-287.

Tomonaga, M., Matsuzawa, T., Fujita, K., \& Yamamoto, J. (1991). Emergence of symmetry in a visual conditional discrimination by chimpanzees ( $P a n$ troglodytes). Psychological Reports, 68, 51-60.

Traina, F., \& Pessotti, I. (1964-1965). Esperienze di discriminazione e di estinzione di um comportamento operante in Ape nera di Sicília. Rassegna di Psicologia Generale e Clinica, 7, 1-12.

Wilkinson, K. M., \& McIlvane, W. J. (1997). Blank comparison analysis of emergent symbolic mapping by young children. Journal of Experimental Child Psychology, 67, 115-130.

Zhang, S. W., Lehrer, M., \& Srinivasan, M. V. (1999). Honeybee memory: navigation by associative grouping and recall of visual stimuli. Neurobiology of Learning and Memory, 72, 180-201.

Zygmont, D. M., Lazar, R. M., Dube, W. V., \& McIlvane, W. J. (1992). Teaching arbitrary matching via sample stimulus-control shaping to young children and mentally retarded individuals: A methodological note. Journal of Experimental Analysis of Behavior, 57, 109-117. 


\section{Lo que el Cognoscitivismo no entiende del Conductismo J.A. ROBINSON, Comunidade Los Horcones Editora Walden Dos}

\section{Resenha de Publicação Recente}

A literatura da Análise do Comportamento e do Behaviorismo Radical foi recentemente brindada (novembro de 2003), com um novo livro da Coleção "Análisis de la Conducta y sus implicaciones", editado em espanhol pela comunidade experimental Los Horcones. O livro busca exatamente esmiuçar e esclarecer, em linguagem quase coloquial, mitos e fatos a respeito de duas questôes: 1) em que medida e sob que critérios a Análise do Comportamento inclui os eventos privados como parte de seu objeto, sem sinonimizá-los com eventos mentais; 2) qual a correta interpretação de Skinner acerca da causalidade (melhor seria, da descrição de relaçôes funcionais, na perspectiva machiana) do comportamento humano.

O livro que nos apresenta J. A. Robinson (cofundador da Comunidad Los Horcones, criada em outubro de 1973), está posto em 163 páginas de texto claro, sem redundâncias e rebuscamento. O livro, nas próprias palavras do autor, foi “....escrito para o público em geral e, por isso, evitamos uma linguagem técnica e sofisticada... também o escrevemos pensando nos estudantes das carreiras de psicologia, educação, lingüística, filosofia e outras disciplinas interessadas na conduta ou comportamento humano". (p. 15)

É coerente, portanto, que J. Robinson tenha utilizado a combinação de duas estratégias: uma construção ficcional do cenário onde ocorre a narrativa (um estudante de Psicologia mexicano deixa sua comunidade e defronta-se com as críticas ao suposto reducionismo explicativo behaviorista, apontado por seus professores durante as aulas da universidade), contrastada com um texto descritivo e referenciado em citações de trechos da obra skinneriana, objeto central do livro. "Lo que el Cognoscitivismo no entiende Del Conductismo" constitui, de certo modo, uma operacionalização conceitual do que o Behaviorismo Radical concebe como explicação do comportamento, ao mesmo tempo em que analisa criteriosamente algumas críticas, quase sempre fundadas no desconhecimento teórico e, via de regra, encontradas na literatura de Psicologia e em segmentos do contexto acadêmico.

\section{Summary of Recent Publication}

The literature of Behavior Analysis and Radical Behaviorism was recently (November, 2003) augmented by a new book of the Collection "Análisis de la Conducta y sus implicaciones" (edited in Spanish) by the experimental community Los Horcones. The book aims to specify and clarify myths and facts concerning two issues: 1) In which measure and under which criteria Behavior Analysis includes the private events as part of its object without making them synonyms of mental events; and 2) The correct interpretation of Skinner concerning the causality of the human behavior (i.e., description of functional relations, in the machian perspective)

The book by J. Robinson (co-founder of the Comunidad Los Horcones, created in October of 1973) has 163 pages of well written text. According to the author's words, it was "... written for the public in general and, therefore, we avoided jargon and sophisticated language... also we wrote it thinking about students of psychology, education, linguistics, philosophy and others disciplines interested in human behavior". (p. 15)

Consistent to that, Robinson used the combination of two strategies. Firstly, a fictional construction of the scene where the narrative occurs (a Mexican student of Psychology leaves his community and is confronted by his teachers criticisms to the presumpted reducionism of behavioristic explanations, during classes at the university. Secondly, and in contrast with the first strategy, he uses a descriptive and referenced text with quoted ideas of the skinnerian work, which is the main theme of the book. "Lo que el Cognoscitivismo no entiende Del Conductismo" constitutes, in a certain way, a conceptual operationalization of what Radical Behaviorism conceives as explanation of the behavior, and simultaneously he carefuly analyses some of those criticisms, generally based on theoretical lack of knowledge, although frequently found in Psychology literature and segments of the academic context.

Instruções para aquisição do livro no site/Instructions for the acquisition of the book http://www.loshorcones.org. $m x /$ publicaciones.html

\section{KESTER CARRARA ${ }^{1}$}

\footnotetext{
1 Professor adjunto, Departamento de Psicologia e Programa de Pós-graduação em Psicologia do Desenvolvimento e Aprendizagem, UNESP, campus de
} Bauru, SP. 